\title{
Aplikasi 3D Virtual Reality Menggunakan Unity Berbasis Mobile Sebagai Media Pengenalan Lingkungan di SIMK Negeri 1 Indramayu
}

\section{Willy Permana Putraa*, Widi Indriyani ${ }^{*}{ }^{*}$,Fachrul Pralienka Bani Muhammaduthor ${ }^{\mathrm{b} *}$,Damar Nurcahyon ${ }^{*}$}

aTeknik Informatika, Politeknik Negeri Indramayu, Indonesia

bPoliteknik Negeri Indramayu, Indonesia

cPoliteknik Negeri Samarinda, Indonesia

KATA K U N C I

3D

SMK Indramayu

Aplikasi.

\begin{abstract}
A B S T R A K
Dalam pengenalan lingkungan sekolah pada siswa baru, umumnya siswa diajak untuk berkeliling sekolah sehingga calon siswa dapat memahami suasana lingkungan sekolah. SMKN 1 INDRAMAYU sendiri masih menggunakan brosur atau spanduk dalam pengenalan sekolah, oleh karena itu bagaimana mengenalkan SMKN 1 INDRAMAYU kepada calon siswa baru tanpa harus mengajak berkeliling. Dari permasalahan tersebut muncul sebuah gagasan untuk membuat aplikasi yang bisa memperkenalkan lingkungan dan memberi informasi serta bisa dijadikan sebagai media promosi SMKN 1 INDRAMAYU yakni menggunakan teknologi virtual reality untuk memvisualisasikan tempat di dunia nyata ke dalam tampilan 3 Dimensi (3D).
\end{abstract}

KEYWOR D S

3D

SMK Indramayu

Aplication

\begin{abstract}
A B S T R A C T
In introducing the school environment to new students, students are generally invited to tour the school so prospective students can understand the atmosphere of the school environment. SMK 1 INDRAMAYU itself still uses brochures or banners in the introduction of schools, therefore how to introduce SMK 1 INDRAMAYU to prospective new students without having to take a tour. From this problem emerged an idea to create an application that can introduce the environment and provide information and can be used as a promotional medium for SMKN 1 INDRAMAYU, namely using virtual reality technology to visualize places in the real world into a 3 Dimensional (3D) display.
\end{abstract}

TERSEDIA ONLINE

31 Oktober 2019

Pendahuluan

Pada perkembangan teknologi yang sudah modern ini hampir semua operasional sudah didukung dengan aplikasi berbasis teknologi. Hal ini dikarenakan perkembangan teknologi yang semakin hari semakin pesat, sehingga banyak inovasi baru yang muncul dari teknologi. Salah satunya inovasi yang terbaru saat ini yaitu virtual reality.

Virtual Reality merupakan teknologi yang memungkinkan seseorang melakukan suatu simulasi terhadap suatu objek nyata dengan menggunakan komputer yang mampu membangkitkan suasana 3 dimensi sehingga membuat pemakai seolah-olah terlibat secara fisik. 3 Dimensi (3D) adalah bentuk dari benda yang memiliki panjang, lebar dan tinggi. Setiap bangun 3 dimensi memiliki kapasitas yang disebut dengan volume. Contoh teknologi virtual reality yang cukup sederhana adalah Google Cardboard dan VRBox. Teknologi virtual reality ini biasanya digunakan pada bidang medis, property, arsitektur, penerbangan, hiburan, dan pengenalan lingkungan.

Pengenalan lingkungan pada sekolah, biasanya berkeliling di area sekolah pada siswa baru dan SMKN 1 INDRAMAYU sendiri masih menggunakan brosur atau spanduk dalam pengenalan sekolah. Sebenarnya sudah cukup dalam hal tersebut, tetapi jika menggunakan media tersebut sudah banyak digunakan oleh sekolah untuk melakukan pengenalan sekolah pada umumnya. Dengan menggunakan media yang berbeda dengan

*Corresponding author: Teknik Informatika, Politeknik Negeri Indramayu, Indonesia

Email address: widi.indriyani@gmail.com

Published by FMIPA UNSRAT (2019) 
yang lain dalam melakukan pengenalan sekolah menggunakan teknologi virtual reality, sehingga dapat menarik para pengguna umumnya yang ingin mengetahui dan mengenal lingkungan sekolah dengan menggunakan objek 3D. terdapat beberapa yang digunakan untuk membangun model 3D salah satunya adalah Unity. Berdasarkan permasalahan tersebut, maka dibuat "Aplikasi 3D Virtual Reality Menggunakan Unity Berbasis Mobile Sebagai Media Pengenalan Lingkungan SMKN 1 INDRAMAYU".

\section{Material dan Metode}

Metode dalam perancangan aplikasi ini menggunakan Prototype Model dimana sistem ini nantinya dapat dikembangkan kembali. Dibawah ini adalah rancangan penelitian dalam pembuatan Aplikasi 3D Virtual Reality Menggunakan Unity Berbasis Mobile Sebagai Media Pengenalan Lingkungan SMKN 1 INDRAMAYU agar dalam pengerjaannya dapat terselesaikan sesuai dengan rancangan yang telah dibuat.

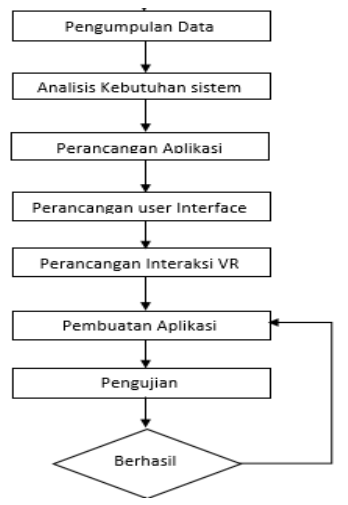

Gambar 1. Tahapan Penelitian

Menurut Sutabri (2012) dalam Parassa (2018) Aplikasi merupakan alat terapan berfungsi khusus dan terpadu sesuai kemampuan yang dimilikinya.

Perancangan aplikasi yang dibangun berbasis Android. Dalam penerapannya akan dibuat sebuah objek 3D yang akan menampilkan gedung-gedung dan lingkungan yang ada di SMKN 1 Indramayu, kemudian setelah objek 3D sudah dibuat pengguna akan membutuhkan perangkat tambahan yaitu kacamata VR Google CardBoard untuk membantu pengguna agar bisa masuk dan berinteraksi secara langsung dalam dunia 3D. Berikut tahapan perancangan aplikasi virtual reality yang dapat dilihat pada gambar 2 .

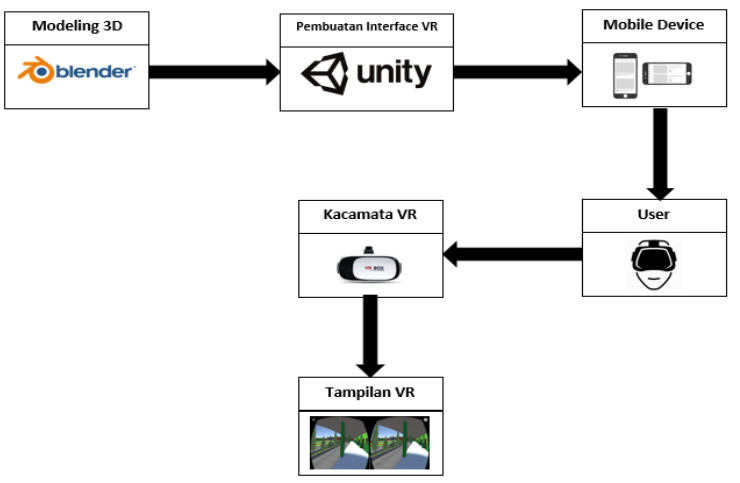

Gambar 2 Rancangan Aplikasi

Hasil dan Pembahasan

Dibawah ini merupakan tabel dari hasil pengujian menggunakan metode black box testing dari Aplikasi 3D Virtual Reality.

\begin{tabular}{|c|c|c|c|c|c|}
\hline $\mathrm{N}_{0}$ & $\begin{array}{l}\text { Skenario } \\
\text { Pengujian }\end{array}$ & Test Case & \begin{tabular}{|l|} 
Hasil Yang \\
Ditampilkan
\end{tabular} & Hasil Pengujian & Kesimpulan \\
\hline 1 & $\begin{array}{l}\text { Menjalanka } \\
\text { n Aplikasi } \\
\text { dengan } \\
\text { menekan } \\
\text { tombol icon } \\
\text { aplikasi }\end{array}$ & & \begin{tabular}{|l|} 
Jika suda menekan \\
tombol Aplikasi \\
makan akan \\
menampilkan menu
\end{tabular} & $1=$ & $\begin{array}{l}\text { Sesuai yang } \\
\text { diharapkan }\end{array}$ \\
\hline 2 & $\begin{array}{l}\text { Memilih } \\
\text { Button } \\
\text { Mulai VR } \\
\text { untuk } \\
\text { memulai } \\
\text { berinteraksi } \\
\text { dengan } \\
\text { dunia 3D }\end{array}$ & $O_{\text {main }}$ & \begin{tabular}{|l|} 
Jika sudah \\
menekan tombol \\
Mulai VR maka \\
selanjutnya akan \\
menampilkan dunia \\
3D
\end{tabular} & & $\begin{array}{l}\text { Sesuai yang } \\
\text { di harapkan }\end{array}$ \\
\hline
\end{tabular}

Gambar 2. Pengujian Menggunakan

\section{Kesimpulan}

Aplikasi 3D Virtual Reality Menggunakan Unity Berbasis Mobile Sebagai Media Pengenalan Lingkungan SMKN 1 INDRAMAYU bisa digunakan sebagai pengenalan lingkungan sekolah dan media promosi SMKN 1 INDRAMAYU serta Aplikasi 3D Virtual Reality Menggunakan Unity Berbasis Mobile Sebagai Media Pengenalan Lingkungan SMKN 1 INDRAMAYU memberikan pengalaman kepada siswa baru yang seakan-akan dapat mengitari lingkungan sekolah dengan cara berjalan menggunakan teknologi Virtual Reality.

\section{Daftar Pustaka}

Abidin, Riswan. 2016. Pengertian Virtual Reality. https://teknojurnal.com Diakses pada tanggal 3 Maret 2019.

Andika, Dwiky. 2018. Pengertian Virtual Reality. https://www.it-jurnal.com/pengertian-virtualreality/. Diakses pada tanggal 1 Maret 2019.

Ardhianto, Eka. 2012. Pengertian Blender 3D. Jurnal Teknologi Informasi DINAMIKA Universitas Stikubank.

Filus, Teo . 2017 . Pengertian Bahasa Pemrograman C Sharp (C\#). https://www.codepolitan.com . Diakses pada tanggal 1 Maret 2019.

Hendratman, Hendi. 2015. Blender 3D Modelling. Bandung : Informatika.

Hernawan, Achmed. 2018. Pengertian Android. https://windowsku.com. Diakses Pada tanggal 02 Mei 2019.

International Design School . 2016 . Pengertian 3 Dimensi. https://idseducation.com . Diakses pada tanggal 10 Maret 2019

Kurniawan, Widi. 2013. Pengertian Texturing. Jurnal Universitas Kristen Satya Wacana Salatiga. Diakses Pada tanggal 02 Mei 2019.

Parassa, Y., Bijang, N. L., \& Pesik, M. U. (2018, October). Online Tourism Architecture Design in North Sulawesi Province. In 2018 International 
Conference on Applied Science and Technology (iCAST) (pp. 536-539). IEEE. 